Artigo Original

Original Article

\title{
Perfil Sociodemográfico e iniciação esportiva na corrida Orientação no Brasil: um estudo transversal
}

\section{Sociodemographic Profile and Initiation in Orienteering Running in Brazil: A Sectional Study}

Fábio Solagaistua de Matos ${ }^{\S 1}$; Gustavo de Rezende Corrêa ${ }^{2} \mathrm{PhD}$

Recebido em: 7 de janeiro de 2021. Aceito em: 27 de abril de 2021.

Publicado online em: 30 de junho de 2021.

DOI: 10.37310/ref.v90i1.2711

\section{Resumo}

Introdução: A Orientação, praticada no Brasil desde os anos 70, encontra dificuldades na popularização e no aumento consistente de participantes em suas principais competições. Nessa condição, torna-se um esporte subestimado no que diz respeito à busca por recursos financeiros e aspectos de visibilidade midiática, visto que possui um altíssimo grau de atratividade envolvendo fatores físicos e cognitivos, tendo como local de prática os cenários naturais que por si só despertariam interesse instantâneo como acontece em vários países do continente europeu.

Objetivo: Descrever as características sociodemográficas do atleta brasileiro da Orientação e examinar a temporalidade do início nessa prática esportiva.

Métodos: Estudo observacional, transversal, no qual foi utilizado um questionário online por meio do Formulários Google, contendo 68 perguntas. Participaram da pesquisa 638 atletas do Esporte Orientação, de ambos os sexos. Foram

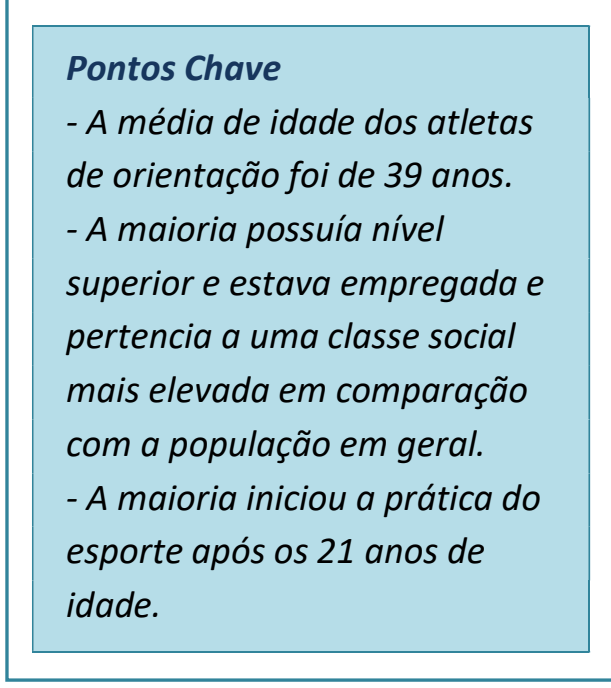
realizadas análises estatísticas descritivas em termos de média, desvio padrão e porcentagem.

Resultados: Os praticantes, com a faixa etária variando dos 13 aos 77 anos(média 39,3 $\pm 13,7$ ), pertenciam a uma classe social mais elevada, com formação acadêmica privilegiada e teve a iniciação no esporte após os 21 anos de idade

Conclusão: Os praticantes de Orientação no Brasil fazem parte de uma faixa socioeconômica mais alta, destoando da média da população nacional. Os resultados indicam que pode haver necessidade de estratégias de desenvolvimento da modalidade que promovam a inclusão esportiva de pessoas de camadas sociais de renda mais baixa.

Palavras-chave: corrida de orientação, características sociodemográficas, esporte.

\begin{abstract}
Introduction: Orienteering running is practiced in Brazil since the 70's. There are difficulties to popularize and consistently increase the number of participants in its main competitions. Thus, it is a sport undervalued about the search for financial resources and aspects of media visibility, in despite that it presents a high degree of attractiveness involving physical and cognitive factors, and having as place of
\end{abstract}

${ }^{\S}$ Autor correspondente: Fábio Solagaistua de Matos - e-mail: fsolagaistua@gmail.com Afiliações: ${ }^{1}$ Clube de Orientação da Universidade Federal do Rio de Janeiro (UFRJ); ${ }^{2}$ Fundação Técnico Educacional Souza Marques. 
practice natural scenarios, that by themselves would arouse instant interest, as happens in several countries on the European continent.

Objective: To describe the sociodemographic characteristics of the Brazilian athlete in Orienteering running and examine the temporality of the beginning of this sport.

Methods: Observational, cross-sectional study, in which an online questionnaire was used through Google Forms, containing 68 questions. A total of 638 athletes from Sport Orienteering, of both sexes, participated in the research. Descriptive statistical analyzes were performed in terms of mean, standard deviation and percentage.

Results: Practitioners, with ages ranging from 13 to 77 (mean $39 \pm 13,7$ ) years old, belonged to a higher social class, with higher education, and initiation in sport was over 21 years old.

Conclusion: Orienteering practitioners in Brazil are part of a higher socioeconomic group, which differs from the average of the world population. The results indicate that there may be a need for development strategies to promote sports inclusion for people from lower-income social strata.

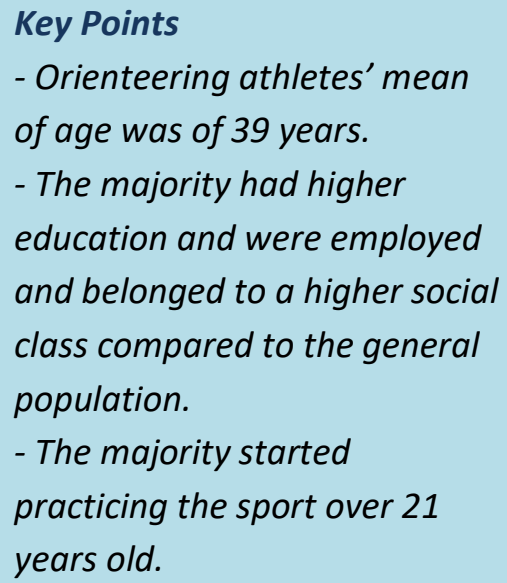

\section{Perfil Sociodemográfico na e iniciação esportiva em corrida de Orientação no Brasil: um estudo transversal}

\section{Introdução}

\section{Corrida de Orientação: Apresentação e aspectos históricos}

Orientação é um esporte que, além do preparo físico necessário à competição que envolve corrida, demanda grande atividade cognitiva relacionada a processos de tomada de decisão(1). Sua realização requer habilidades de navegação usando um mapa topográfico e uma bússola, sendo que no percurso há rota demarcada. Assim, o atleta escolhe sua própria estratégia para encontrar os pontos de controle, os quais são marcados com precisão no mapa e no solo onde são representados por prisma laranja e branco(2). É um esporte individual e, nesse contexto, os atletas devem fazer seu percurso sem nenhuma assistência externa(3). Normalmente, a Orientação é realizada em terrenos variados. Nas origens escandinavas, isso significava floresta, mas também é comum em área livre, pastagem, pântano e outros terrenos mistos. Com o passar dos anos, tornou-se comum a realização de competições, também, em ambientes urbanos(4).
A Orientação teve suas origens em um exercício de treinamento militar e desenvolveram-se muitas variações. A mais antiga e popular é a forma a pé, configurando-se na corrida de Orientação(3).

O termo "Orientação" foi introduzido em 1886 na Academia Militar Sueca Karlberg(3). Lá, passou do treinamento militar para um esporte competitivo para oficiais militares. A primeira competição civil foi realizada na Noruega em 1897(3). Os locais foram escolhidos em parte por sua beleza(3). O esporte ganhou popularidade nos anos 30, com a invenção de bússolas baratas e confiáveis. Mais de 250 mil suecos eram praticantes, em 1934, e a orientação se espalhou para outros países como Finlândia, Suíça, União Soviética e Hungria. Após a Segunda Guerra Mundial, a modalidade espalhou-se por toda a Europa e Ásia, América do Norte e Oceania(3). Em 1961, dez nações europeias fundaram a Federação Internacional de Orientação (International Orienteering Federation: IOF), que apoiou a fundação de muitas federações nacionais. 
Durante esse tempo, a Orientação permaneceu mais popular na Escandinávia, sendo que desde 1965 é realizado, anualmente, o maior encontro internacional da modalidade, o O-Ringen que conta com cerca de 20.000 concorrentes(5). Atualmente, a IOF possui 76 federações membros(6).

No Brasil, em 1970, militares viajaram à Europa para observar competições e, a partir disso, organizaram as primeiras competições militares no Brasil(7). Em 1983, alguns mapeadores nórdicos elaboraram mapas para realização de eventos, contribuindo para o desenvolvimento do esporte entre brasileiros. Em seguida, o Serviço Geográfico do Exército Brasileiro, objetivando promover o esporte, organizou uma competição com 14 entidades civis e militares(8). Também nesse ano, o XVII Campeonato Mundial Militar de Orientação foi realizado em Curitiba, no estado do Paraná(9).

No final da década de 1980, realizou-se uma campanha de promoção do esporte em todo o território brasileiro. A partir disso, vários clubes foram fundados, sendo base para as federações regionais e competições abertas ao público civil. Somente em 1996 começou o processo de fundação da Confederação Brasileira de Orientação (CBO), confirmado três anos depois(8).

Em 1992, a corrida de Orientação foi incluída como disciplina no curso de Educação Física da Universidade Federal do Rio de Janeiro, e em 2004, inserida no projeto social Sou Feliz. Em 1999, a CBO desenvolveu, através da Política Nacional para o Desenvolvimento do Esporte Orientação (PNDO), uma proposta pedagógica, o Projeto Escola da Natureza, que preconizava a presença da Orientação nos currículos escolares, em todos os níveis(10).

\section{Corrida de Orientação atualmente}

$\mathrm{Na}$ atualidade, observa-se que, em comparação com a Suécia, país de origem da modalidade, com uma população de aproximadamente 10 milhões(11), em 2018, contava com 75.000 atletas federados(12), enquanto o Brasil, com uma população que excede os 210 milhões de habitantes(13) apresenta menos de 20.000 atletas filiados contados ao longo de toda sua história(14).

O objetivo do presente estudo foi descrever as características sociodemográficas do atleta brasileiro de Corrida de Orientação e examinar a temporalidade do início nessa prática esportiva.

\section{Métodos}

\section{Desenho de estudo e amostra}

Pesquisa observacional, transversal e exploratória, de metodologia qualiquantitativa, para a qual foi desenvolvida uma entrevista estruturada. sendo que o método escolhido para análise de conteúdo teve como base os conceitos de Bardin(15). A pesquisa contou com o apoio da $\mathrm{CBO}$ e foram convidados para participar todos os atletas federados (aproximadamente dois mil atletas com cadastro ativo). Compreendendo o discurso científico como forma de problematizar o senso comum e propor perspectivas de reflexão e ação, é possível compreender a pesquisa como meio de construir conhecimento e que uma investigação se destina a resolver um problema(16). Porém, há uma ordem de prioridade em que a ciência se faz, por meio de pesquisa e com metodologia.

$O$ critério de inclusão foi ser filiado à CBO no ano de realização da pesquisa (2020). Os critérios de exclusão foram: não ter participado de nenhuma prova oficial nos últimos 2 anos, anteriores a pesquisa; e não assinalar o concordo (botão no formulário online), aceitando os termos da pesquisa informados no Termo de Consentimento Livre e Esclarecido (TCLE).

\section{Aspectos éticos}

$\mathrm{O}$ estudo foi avaliado, quanto aos aspectos éticos da pesquisa envolvendo seres humanos, e aprovado pelo Comitê de Ética da Escola de Medicina Souza Marques, sob o protocolo CAAE 33730120.0.0000.5239 Para os atletas menores de idade, foi necessário que os 
responsáveis enviassem um Termo de Assentimento Livre e Esclarecido (TCLE).

\section{Instrumento}

Para a coleta de dados foi desenvolvido um questionário online por meio do Formulários Google que se apresenta de forma integral no Apêndice 1. O questionário buscou investigar o perfil sociodemográfico, a iniciação esportiva e aspectos de consumo relacionados aos eventos esportivos dos participantes e foi composto 68 perguntas. A primeira questão perguntava se o atleta possuía mais de 18 anos de idade, se tinha lido o TCLE e se concordava em participar da pesquisa ou, sendo menor de 18 anos, se o seu responsável o autorizava a participar da pesquisa. As demais questões foram distribuídas nos seguintes grupos de informações: características sociodemográficas - Questões: 2-21 (religião, orientação sexual, estado civil, filhos, escolaridade, profissão, etnia, renda, residência, estado onde reside, se possui veículo automotor e se é portador de deficiência física); perfil complementar Questões 22-25 (informações de hábitos alimentares e de lazer) - (características de atleta). e outras informações relacionadas à corrida de Orientação) - Questões 26-30 e 33-68, deste último bloco de perguntas, fizeram parte deste estudo apenas as questões 33 (Q33) e 43 (Q43). A Q33 pergunta em que meio conheceu o esporte e a Q43 pergunta o que mais lhe desagradou em sua primeira prova de Orientação? (independente do resultado) .

Utilizou-se para a variável sexo somente as categorias masculino e feminino, seguindo a caracterização da própria modalidade.

\section{Procedimento experimental}

$\mathrm{O}$ questionário foi aplicado durante $\mathrm{o}$ período de isolamento social decorrente da pandemia COVID-19 e buscou alcançar o maior número de pessoas possível.

\section{Análise estatística}

Foram realizadas análises estatísticas descritivas em termos de média, desvio padrão e porcentagem. A margem de erro para o tamanho amostral foi de $3,7 \%$.

\section{Resultados}

Participaram da pesquisa 638 atletas do Esporte Orientação, sendo $28,21 \%$ do sexo feminino $(n=180)$ e $71,79 \%$ do sexo masculino $(\mathrm{n}=458)$, com a faixa etária variando dos 13 aos 77 anos $(\mathrm{M}=39,3 \pm$ 13,7). A maioria declarou-se católica $(49,12 \%)$ e heterossexual $(94,05 \%)$ (Tabela $1)$.

Dos cerca de 2.000 orientistas elegíveis para participar do estudo, 752 (37,6\%) praticantes responderam ao questionário. Depois de aplicados os critérios de exclusão, dados de 23 atletas foram retirados por serem menores de idade e não terem apresentado o TCLE assinado pelos responsáveis, dois convidados não concordaram em participar da pesquisa e 89 atletas foram retirados do estudo pelo critério de exclusão de não competir há mais de dois anos. Assim, a amostra foi composta por 638 participantes, que contavam com média de idade de 39,3 $( \pm 13,7)$ anos, sendo que a faixa etária que apresentou maior número de atletas foi a de 35 a 50 anos (Tabela 1). A maioria dos participantes era de cor branca $(61,29 \%)$, seguida de parda $(32,60 \%)$ que, juntos, somavam 93,7\%. Também a maioria exercia atividade profissional no meio civil $(65,37 \%)$ e começou a praticar o Esporte Orientação após os 21 anos de idade $(68,5 \%)$ e possuía pelo menos um filho $(59,56 \%)$.

Aproximadamente, metade dos entrevistados $(50,63 \%)$ conheceu a Orientação no meio civil (Q33) (Figura 1B).

A maioria dos atletas declarou que o que mais desagradou em sua primeira participação foi possuir pouco conhecimento acerca do esporte (Q43) (Figura 1A).

Meio em que conheceu o esporte; 1CDistribuição dos orientistas brasileiros por região da Federação, em negrito o número absoluto de respondentes, por região e entre parênteses a proporção percentual no total de entrevistados ; 1D- Número de residentes na mesma casa.

A distribuição geográfica dos praticantes está localizada, majoritariamente, nas regiões litorâneas do Brasil (Figura 1C). 
Apenas 35\% dos atletas residiam sozinhos e a maioria apresentava de 2-4 pessoas na residência (Figura1D).

A Figura 2 exibe a distribuição dos dados de renda, estado civil, escolaridade e casa própria. A maior parte dos atletas possuía renda pessoal entre 1-8 salários-mínimos $(73,04 \%)$ (Figura 2A), era de casados ou em união estável $(60,35 \%)$ (Figura 2B), possuía curso superior $(45,77 \%)$ (Figura 2C). A maioria dos orientistas entrevistados era possuidora de casa própria $(68,03 \%)$ (Figura 2D).

\section{Discussão}

Até onde se sabe, este foi o primeiro estudo a investigar o perfil sociodemográfico de atletas de Orientação no Brasil, o destaca sua relevância. Os principais achados foram que a maioria dos atletas percebiam renda pessoal entre 1-8 salários-mínimos $(73,04 \%)$, a temporalidade do início da prática demonstrou ser tardia (após os 21 anos de idade) $(68,50 \%)$ e a escolaridade dos atletas foi, predominantemente, de nível superior $(45,77 \%)$. Outro resultado importante foi que a proporção de atletas que conheceram o esporte no meio civil foi semelhante aos que o conheceram no meio militar .

A renda pode ser considerada como um possível fator limitante para a propagação do esporte é o nicho econômico que tem alcançado, sendo seus praticantes pertencentes às classes mais altas, em especial à classe $\mathrm{A}$, já que $26,96 \%$ possuem renda pessoal superior a oito saláriosmínimos, e se considerada a renda familiar, esse número sobe para $44,67 \%$, enquanto a renda média do cidadão brasileiro é ligeiramente superior a dois saláriosmínimos(13).

A alta condição financeira do orientista também foi relatada em estudo sueco mostrando que trabalhadores de colarinho branco e altos executivos compõem $59 \%$ da população(24). Em estudo semelhante, dessa vez realizado na Austrália, também foi destacado $\mathrm{o}$ alto posicionamento profissional dos orientistas daquele país, refletindo também no nível educacional dos
Tabela 1 - Características sociodemográficas da amostra e idade de início da prática do Esporte Orientação entre atletas brasileiros federados $(\mathrm{N}=638)$

\begin{tabular}{|c|c|c|}
\hline Variáveis & $\mathbf{n}$ & $\%$ \\
\hline \multicolumn{3}{|l|}{ Idade } \\
\hline 13 aos 20 anos & 79 & 12,38 \\
\hline 21 aos 35 anos & 167 & 26,17 \\
\hline 35 aos 50 anos & 248 & 38,87 \\
\hline Acima de 50 anos & 144 & 22,57 \\
\hline \multicolumn{3}{|l|}{ Sexo } \\
\hline Feminino & 180 & 28,21 \\
\hline Masculino & 458 & 71,79 \\
\hline \multicolumn{3}{|l|}{ Etnia } \\
\hline Amarela/Asiática & 5 & 0,78 \\
\hline Branca & 391 & 61,29 \\
\hline Parda & 208 & 32,60 \\
\hline Preta & 31 & 4,86 \\
\hline Indígena & 3 & 0,47 \\
\hline \multicolumn{3}{|l|}{ Profissão } \\
\hline Militar & 221 & 34,63 \\
\hline Professor & 78 & 12,22 \\
\hline Estudante & 55 & 8,62 \\
\hline Outras & 284 & 44,53 \\
\hline \multicolumn{3}{|l|}{ Crença Religiosa } \\
\hline Agnóstico/Ateu & 83 & 13 \\
\hline Católica & 316 & 49,12 \\
\hline Evangélica & 109 & 17,1 \\
\hline Outra & 252 & 52,05 \\
\hline Prefiro não & 37 & 5,8 \\
\hline \multicolumn{3}{|l|}{ Orientação Sexual } \\
\hline Bissexual & 16 & 2,5 \\
\hline Heterossexual & 600 & 94,05 \\
\hline Homossexual & 16 & 2,5 \\
\hline Prefiro não & 6 & 0,95 \\
\hline \multicolumn{3}{|l|}{ Praticantes na } \\
\hline 1 & 384 & 384 \\
\hline 2 & 178 & 178 \\
\hline 3 & 53 & 53 \\
\hline Mais de 3 & 23 & 3,6 \\
\hline \multicolumn{3}{|l|}{ Filhos } \\
\hline 0 & 258 & 40,44 \\
\hline 1 & 125 & 19,59 \\
\hline 2 & 177 & 27,74 \\
\hline 3 & 62 & 9,72 \\
\hline Mais de 3 & 16 & 2,51 \\
\hline \multicolumn{3}{|l|}{ Idade de início na } \\
\hline Menos de 10 anos & 15 & 2,35 \\
\hline $10-15$ anos & 66 & 10,34 \\
\hline 16-20 anos & 120 & 18,81 \\
\hline 21-34 anos & 253 & 39,66 \\
\hline $35-50$ anos & 154 & 24,14 \\
\hline Mais de 50 anos & 30 & 4,7 \\
\hline
\end{tabular}


A

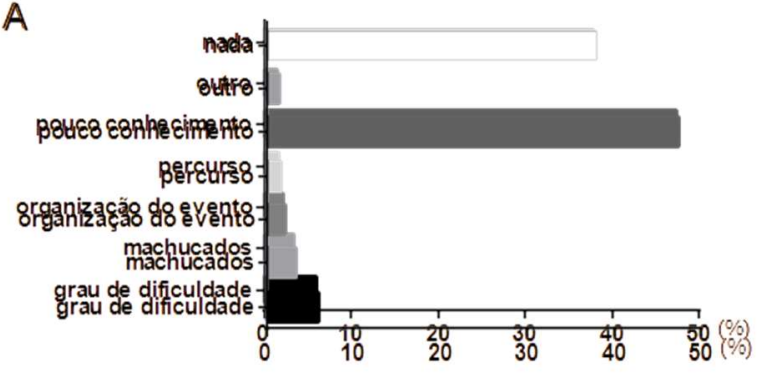

Č

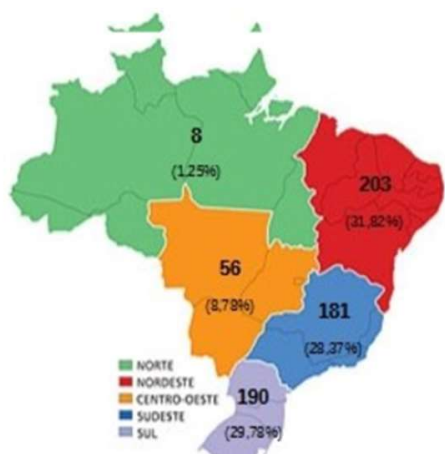

B
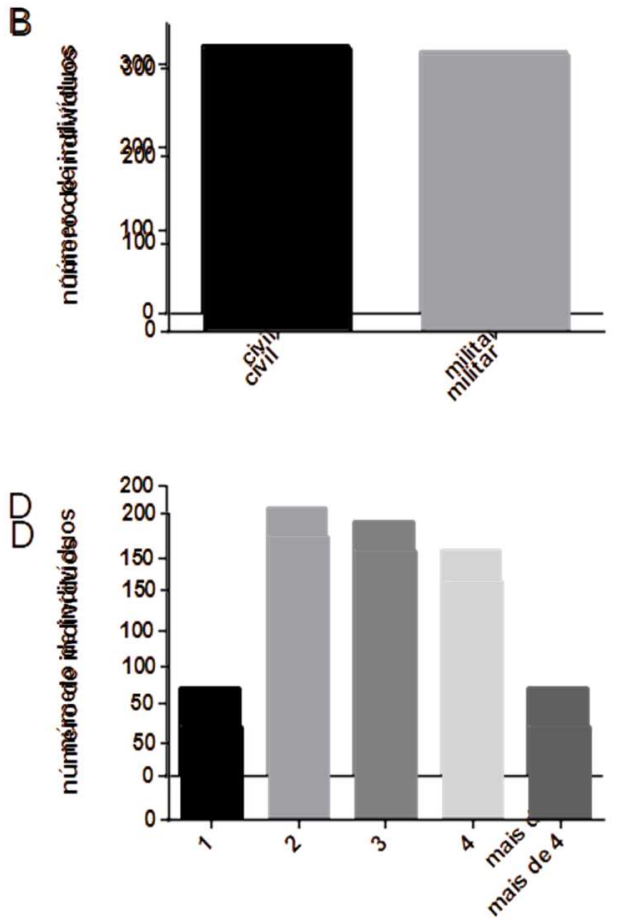

Figura 1 - 1A- Descrição dos fatores que desagradaram na primeira participação; 1B- Meio em que conheceu o esporte; 1C- Distribuição dos orientistas brasileiros por região da Federação, em negrito o número absoluto de respondentes, por região e entre parênteses a proporção percentual no total de entrevistados ; 1D- Número de residentes na mesma casa.
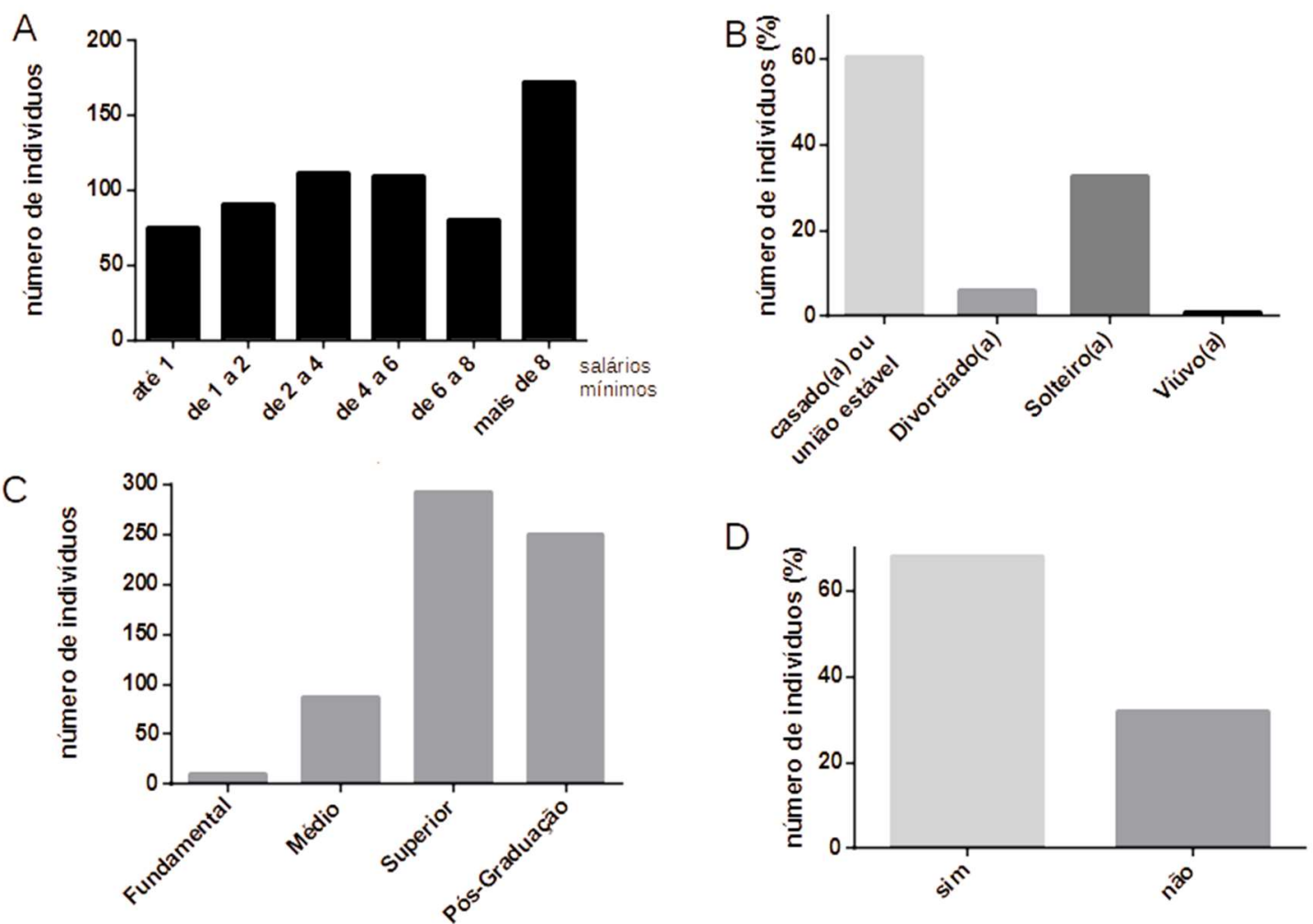

Figura 2 - 2A - Renda individual (salários-mínimos); 2B - Estado Civil (porcentagem); 2C Escolaridade; 2D - Percentual de indivíduos que possuem, ou não, casa própria. 
praticantes acima dos 24 anos, onde $65 \%$ dos orientistas possuem ao menos uma graduação(25).

Quanto à temporalidade da iniciação no desporto, os resultados mostraram ser tardia, dados semelhantes aos do estudo de Koukoris(19), realizado com o público grego praticante de Orientação, em que $75,6 \%$ dos praticantes tiveram o primeiro contato com a Orientação após os 19 anos.

A comparação com a Grécia é justificada pelo fato de também ser um país em desenvolvimento na Orientação, tendo iniciado as suas atividades no ano de 1997. Enquanto no Brasil, a proporção de atletas que iniciaram sua participação na modalidade antes dos 10 anos de idade foi de 2,35\%, na Suécia, país com mais tradição na modalidade, $19,1 \%$ dos praticantes iniciaram com 6 anos e 81,2\% iniciaram antes dos 21 anos(20).

A iniciação tardia prejudica a qualidade na formação de atletas de alto nível. Segundo Celestino e colegas, diversos autores estipularam a necessidade de uma prática acumulada de pelo menos 10 anos para que um alto nível de performance seja alcançado, sendo que esse início deve ser durante a infância(21). Por se tratar de um esporte onde o desenvolvimento técnico e tático de alto nível é complexo. Palmer, em 1984 disse estar convencido que a base técnica tem que ser trabalhada antes dos 16 anos(22), assim como Martland definiu as prioridades na montagem de um programa técnico para meninos e meninas dos 13 aos 15 anos(23). No contexto da iniciação tardia, há que se considerar a falta de um programa específico para introdução esportiva para adultos, já que os livros estrangeiros apresentam abordagem para iniciantes crianças. Nesse contexto, há uma preocupação de que muitos atletas/praticantes em potencial podem deixar de fazer parte do esporte por conta de experiências negativas, principalmente ocasionadas pela falta de um conhecimento técnico do esporte mais aprofundado.

Quanto ao nível de escolaridade, a maioria dos entrevistados tinha curso superior e/ou pós-graduação, resultado que difere da população brasileira que apresenta apenas $13 \%$ de cidadãos nessa condição(13). Comparando com os orientistas brasileiros com 24 anos ou mais, nosso público é mais seleto que o australiano, pois, $81,29 \%$ possuem ao menos uma graduação. Sendo assim, as classes menos favorecidas podem encontrar mais dificuldade para o conhecimento do esporte e consequente adesão à modalidade, ficando estes muitas vezes restritos aos programas sociais, voltados para o esporte, encontrados em baixa escala pelo território nacional.

Os projetos escolares podem não necessariamente implicar na afiliação das crianças nas federações estaduais ou na $\mathrm{CBO}$, ficando restrita à atividade pedagógica sem o intuito de inserção nas competições.

$\mathrm{O}$ conceito de que o esporte Orientação possui uma natureza militar deve ser revisto, com base nos nossos dados, que apresentam que aproximadamente metade dos praticantes do Brasil conheceu o esporte em ambiente civil, quebrando paradigmas de que se trata de um esporte militar, respeitando o histórico de sua inclusão no Brasil(17). Tal fato, pode ser decorrente da criação dos clubes de Orientação, das Federações estaduais e da CBO, todas essas entidades civis. Soma-se a isso a formação de profissionais de Educação Física, que introduziram no ambiente escolar, após contato com o esporte em instituições de ensino superior. A inclusão da Orientação como disciplina em universidades foi fator contribuinte e de alta relevância para disseminação.

Com o interesse de conhecer o perfil do praticante de Orientação no Brasil, esta pesquisa mostrou que mesmo com a população brasileira sendo de maioria feminina(13), a modalidade não se apresenta da mesma maneira, muito provavelmente por influência de sua origem no ambiente militar brasileiro.

Em relação a orientação sexual e crença religiosa, a representação dos atletas de Orientação no Brasil equivale-se à representação da população brasileira(13).

Em relação à etnia, a população brasileira, segundo os dados da Pesquisa Nacional por 
Amostra de Domicílios (PNAD), realizada em 2019(18), 42,7\% dos brasileiros se declararam como brancos, 46,8\% como pardos, 9,4\% como pretos e 1,1\% como amarelos ou indígenas. Entre os orientistas, a maioria declarou-se branca $(61,29 \%)$, seguida de parda (32,6\%), assim, a representação étnica do orientista apresenta distinção em relação a população brasileira.

Quanto ao fator que mais desagradou o participante em sua primeira competição, aproximadamente a metade dos entrevistados relatou que possuíam pouco conhecimento do esporte. Muitos atletas têm o seu primeiro contato com a Orientação em um campeonato oficial, o que denota a falta de estrutura de fomento à iniciação esportiva da corrida de Orientação por parte das entidades administrativas e de prática.

Em relação à distribuição geográfica dos atletas por região no Brasil, os achados do presente estudo mostram convergência com a distribuição da população brasileira, sendo as maiores concentrações de atletas correspondentes às regiões mais populosas do Brasil. De semelhante modo, a maioria dos praticantes da Orientação possuía casa própria $(68,03 \%)$, assim como $66,4 \%$ na população brasileira(13), em uma proporção bastante semelhante.

\section{Conclusão}

O objetivo do presente estudo foi descrever as características sociodemográficas do atleta brasileiro de Corrida de Orientação e examinar a temporalidade do início nessa prática esportiva. Os resultados mostraram que o perfil do praticante de Orientação no Brasil pouco se assemelha ao perfil da sociedade brasileira. Mostramos que o desporto é praticado, predominantemente, por classe social mais elevada e a iniciação tardia no esporte são fatores que podem estar associados ao nível de escolaridade dos praticantes, já que o fomento ao esporte parece ter focalizado alunos universitários. Outros estudos devem investigar estratégias para que a iniciação esportiva da corrida de Orientação se dê ainda na infância (idade escolar).

\section{Conclusão}

O objetivo do presente estudo foi descrever as características sociodemográficas do atleta brasileiro de Corrida de Orientação e examinar a temporalidade do início nessa prática esportiva. Os resultados mostraram que o perfil do praticante de Orientação no Brasil pouco se assemelha ao perfil da sociedade brasileira. Mostramos que o desporto é praticado, predominantemente, por classe social mais elevada e a iniciação tardia no esporte são fatores que podem estar associados ao nível de escolaridade dos praticantes, já que o fomento ao esporte parece ter focalizado alunos universitários. Outros estudos devem investigar estratégias para que a iniciação esportiva da corrida de Orientação se dê ainda na infância (idade escolar).

\section{Agradecimentos}

Agradecemos aos participantes deste estudo e ao Grupo de Pesquisa do COUFRJ pela confecção do questionário.

\section{Declaração de conflito de interesses}

Não há nenhum conflito de interesses em relação ao presente estudo.

\section{Declaração de financiamento}

Estudo conduzido sem financiamento.

\section{Referências}

1. Dias A da C, Dantas EHM. A tomada de decisão na orientação. Revista de Educação Física / Journal of Physical Education. 2004;73(2): 6-6.

2. McNeill C. Orienteering: The Skills of the Game. 2nd ed. London: Crowood Press; 1996. $128 \mathrm{p}$.

3. International Orienteering Federation (IOF). Past \& present / IOF / Top International Orienteering Federation. [Online] Available from: https://web.archive.org/web/20080802131 200/http://www.orienteering.org/i3/index. php?\%2Fiof 2006\%2Fiof\%2Fpast_present [Accessed: 24th June 2021]

4. Swiss Orienteering, Schweizer Orientierungslauf-Verband. [Online] Available from: https://www.swissorienteering.ch/de/ [Accessed: 24th June 2021] 
5. O-Ringen. [Online] Available from: https://www.oringen.se/213/english/nonye ar-pages/about-us.html [Accessed: 24th June 2021]

6. International Orienteering Federation (IOF). National Federations | International Orienteering Federation. [Online] Available from: https://orienteering.sport/iof/governanceand-organisation/national-federations/ [Accessed: 24th June 2021]

7. Escola de Educação Física do Exército (EsEFEx). Manual de Orientação. Rio de Janeiro: Exército Brasileiro; 2000.

8. Centro de Capacitação Física do Exército (CCFEx). Manual de Orientação. Rio de Janeiro: Exército Brasileiro; 1994.

9. Maltez MAC. XVII Campeonato Mundial Militar de Orientação. Revista de Educação Física / Journal of Physical Education. [Online] 1984;53(115). Available from: https://revistadeeducacaofisica.emnuvens. com.br/revista/article/view/548 [Accessed: 24th June 2021]

10. Tomelin G. A Inclusão da Orientação nas aulas de Educação Física. Uma visão dos professores da cidade de Foz do Iguaçu. EFDeportes.com. [Online] 2014;8(189) Available from: https://www.efdeportes.com/efd189/aorientacao-nas-aulas-de-educacaofisica.htm [Accessed: 24th June 2021]

11. Sweden Population 2021 (Demographics, Maps, Graphs). [Online] Available from: https://worldpopulationreview.com/countri es/sweden-population [Accessed: 24th June 2021]

12. Svensk Orienteering. [Online] Svensk Orienteering. Available from: https://www.svenskorientering.se/InEnglis h [Accessed: 24th June 2021]

13. Instituto Brasileiro de Geografia e Estatística. IBGE | Projeção da população. [Online] Available from: https://www.ibge.gov.br/apps/populacao/p rojecao/box_popclock.php [Accessed: 24th June 2021]

14. CBO. Confederação Brasileira de Orientação. [Online] CBO. Available from: https://www.cbo.org.br [Accessed: 24th June 2021]
15. Bardin L. Análise de Conteúdo. São Paulo: Edições 70; 2015. 288 p.

16. Gamboa SAS. Pesquisa Qualitativa: superando tecnicismos e falsos dualismos. Revista Contrapontos. 2003;3(3): 393-405.

17. Da Costa, L. (ORG.). Atlas do Esporte no Brasil. Rio de Janeiro: CONFEF, 2006. Available from: http://www.atlasesportebrasil.org.br/index. php [Accessed: 24th June 2021]

18. Instituto Brasileiro de Geografia e Estatística (IBGE). Cor ou raça $|E d u c a|$ Jovens - IBGE. [Online] Available from: https://educa.ibge.gov.br/jovens/conhecao-brasil/populacao/18319-cor-ou-raca.html [Accessed: 24th June 2021]

19. Koukoris, K. Beginners' perspectives of getting involved in orienteering in Greece. Scientific Journal of Orienteering. [Online] 2005;16:18-33. Available from: https://silo.tips/download/scientificjournal-of-orienteering [Accessed: 24th June 2021]

20. Kocbach J. International Orienteering Coaches Conference 2015. [Online] World of $\mathrm{O}$ News. Available from: http://news.worldofo.com/2015/08/23/inte rnational-orienteering-coaches-

conference-2015/ [Accessed: 24th June 2021]

21. Celestino T, Leitão J, Sarmento $H$, Marques A, Pereira A. The Road to excellence in Orienteering: an analysis of elite athletes' life stories. Journal of Physical Education and Sport. 2015;15(2):178-185.

22. Palmer $\mathrm{P}$, editor. The Complete Orienteering Manual. Malborough: Crowood Press; 1998.

23. Martland JR. The Identification of Priorities in a Coaching Programme of Technical Skills in the Sport of Orienteering for Men and Women 13 and 15 Years. Article-index-internationalorienteering-federation A Classes. [Online] 1986;2(2):112-123. Available from: https://www.yumpu.com/en/document/vie w/4834150/article-index-internationalorienteering-federation [Accessed: 24th June 2021]

24. Ottosson T. Swedish Orienteers: A Survey Study. Scientific Journal of Orienteering. 1995;11(1): 31-37. 
44 Rev Ed Física / J Phys Ed - Perfil Sociodemográfico e iniciação esportiva na corrida Orientação

25. Hogg D. The Social and Lifestile Characteristcs of Australian Orienteers. Scientific Journal of Orienteering. 1996(12): 9-18.

26. Blanchard M, Grison B, Ravier P, Buttelli O. Fadigue \& perception de l'effort pendant une course d'orientation. Scientific Journal of Orienteering. 2009;17: 46-54 